\title{
AS DANÇAS CIRCULARES E AS POSSÍVEIS CONTRIBUIÇÕES DA TERAPIA OCUPACIONAL PARA AS IDOSAS
}

\author{
Tânia Maria Assis Fleury* \\ Daniela Tavares Gontijo**
}

\section{Resumo}

O envelhecimento ainda é visto como uma etapa de dificuldades e bastante negligenciada. A mulher, em especial, é privada de expressar seus sentimentos ou mesmo de praticar atividades que lhe proporcionem prazer. O desafio está em adotar atividades que permitam o bem-estar dessa população. Surgem as danças circulares sagradas, em que as participantes se expressam pelo movimento, utilizando somente o corpo, participando ativamente de suas transformações e da modificação social. Assim, realizouse uma pesquisa de campo com doze mulheres, praticantes das danças circulares, no Centro Livre de Artes, localizado em Goiânia (GO), com o intuito de identificar os benefícios destas danças na vida das participantes. De posse dos dados, procurou-se correlacioná-los à Terapia Ocupacional, profissão que busca a manutenção da autonomia e independência do indivíduo bem como sua integração social, a qual pode colaborar com esta prática, e vice-versa, para oferecer melhor qualidade de vida às idosas.

Palavras-chave: Terceira Idade. Mulher. Danças Circulares Sagradas. Terapia Ocupacional.

\section{Introdução}

A pirâmide etária da população mundial e do Brasil vem se modificando especialmente nas últimas décadas. As pessoas vivem mais, devido à revolução médico-sanitária e à queda da taxa de natalidade, porém, esse fato não significa qualidade de vida, principalmente para os idosos (TODARO; JACOB FILHO, 2004).

* Terapeuta Ocupacional, especializanda em Docência Universitária pela Faculdade de Goiás. E-mail: tania.fleury@bol.com.br.

** Terapeuta Ocupacional, docente da Universidade Católica de Goiás, doutoranda em Ciências da Saúde (Convênio Rede Centro-Oeste-UnB/UFGO/UFMT). 
O envelhecimento é um evento progressivo, dinâmico, caracterizado por alterações físico-funcionais, psicológicas, bioquímicas e sociais que tornam a pessoa mais susceptível à influência de fatores intrínsecos e extrínsecos, que precipitam a instalação de enfermidades que podem, por fim, provocar a morte (PAPALÉO NETTO, 2002).

Nessa fase, é comum o preconceito e discriminações sociais, bem como a perda do status econômico, problemas familiares, alterações cognitivas, déficits de concentração, atenção e memória, que induzem o idoso ao sentimento de desesperança e a sensações de inutilidade, abandono, solidão e desilusão.

Envelhecer, nos padrões das sociedades ocidentais atuais, é estar fadado a uma etapa de decadência; aposentar-se da própria vida, principalmente no que diz respeito às mulheres, as quais em sua maioria, pela evolução histórica baseada na submissão e obediência, são privadas de expressarem seus sentimentos ou de realizarem atividades que lhes proporcionam bem-estar e qualidade de vida.

Assim, a adoção de uma nova definição acerca do envelhecimento busca modificar a visão fisiopatológica desse processo. Entretanto, isso não significa a defesa da preservação dos níveis de desempenho de quando se era jovem, mas sim, a conservação do potencial que a pessoa possui para a manutenção de seu desenvolvimento, obedecendo e respeitando os limites individuais, os quais são dependentes das condições de saúde globais, do estilo de vida e da educação (TODARO; JACOB FILHO, 2004).

O grande desafio da sociedade atual passa a ser, então, a adoção de condições de vida mais saudáveis para os gerontes, reduzindo os estados de morbidade que minimizam os transtornos sociais, emocionais, crônicodegenerativos, tal como a incapacidade, invalidez, dependência de terceiros e morte prematura (JACOB FILHO, 1998).

Como maneira de evitar ou impedir esta má qualidade de vida e de contribuir para a longevidade, a participação em grupos de danças circulares é uma alternativa. Esse tipo de dança possibilita a união entre as pessoas, já que existe o simbolismo do círculo e das mãos dadas que estimulam os sentimentos de confiança, igualdade, apoio mútuo, fazendo com que cada indivíduo possa perceber e reconhecer sua importância no tempo e espaço mundiais (BARRETO, 2002; LORTHIOIS, 2002).

Nas danças circulares sagradas, os integrantes são convidados a se expressarem por meio dos gestos e a irem internalizando as sensações que 
eles vivenciam, participando ativamente da transformação pessoal, pelo conhecimento dos domínios corporais, e da modificação social, ou seja, a forma como vêem a sociedade e se enxergam em relação a ela. Estes objetivos e metas vão ao encontro da prática da Terapia Ocupacional que, segundo Lorthiois (2002) e Neistadt e Crepeau (2002), constitui a arte e a ciência capazes de restaurar, fortalecer e desenvolver capacidades e funções, a partir de atividades que possam ter como recurso, o próprio corpo.

Nesse sentido, após revisão bibliográfica relacionada ao envelhecimento, condição da mulher idosa no Brasil e danças circulares como promotora de qualidade de vida, realizou-se pesquisa de campo. Esta foi baseada em instrumento qualitativo e quantitativo, questionário, com o intuito de identificar os benefícios que as danças circulares sagradas podem trazer para as praticantes, para por fim, estabelecer uma conexão entre essa prática e a Terapia Ocupacional como colaboradora mútua da promoção de qualidade de vida.

\section{Instrumentos e Métodos}

A pesquisa de campo apresentou como sujeitos, doze mulheres com idade superior a 60 (sessenta) anos, obedecendo-se à definição cronológica de envelhecimento da Organização Mundial de Saúde (OMS).

Os critérios de inclusão envolveram, além da idade superior a 60 anos, a obrigatoriedade da participação no grupo de danças circulares do Centro Livre de Artes (CLA), situado no Setor Oeste, Goiânia-GO, boa capacidade cognitiva, habilidade para escrita (para responder ao instrumento de coleta de dados) e a concordância com as questões dispostas no Termo de Consentimento Livre e Esclarecido. Os critérios de exclusão foram distúrbios psiquiátricos, déficit cognitivo e a dependência de terceiros para a realização das atividades de vida diária. Não se levou em consideração aspectos como cor, procedência e nível econômico.

O local da pesquisa, CLA, dedica-se às artes para todas as idades. É vinculado a um departamento da Secretaria Municipal de Cultura do Município citado, que atua com a proposta básica de levar o seu integrante a refletir, analisar, pensar, agir e reagir conforme a arte e seus princípios do movimento. Vem desenvolvendo trabalhos específicos com as gerontes há cerca de cinco anos, com o intuito maior de promover socialização e melhorar 
a qualidade de vida, utilizando para esse fim, as danças folclóricas, especificamente, as danças circulares sagradas.

O grupo com o qual se realizou a pesquisa foi coordenado pela pesquisadora e focalizadora Maria Cristina Bonetti, a qual trabalhava com as danças circulares sagradas desde 1994, e quem introduziu esta metodologia no CLA, em 2000.

A coleta de dados foi realizada por meio de uma entrevista semiestruturada, em que houve a combinação de treze perguntas fechadas e uma pergunta aberta, possibilitando às pesquisadoras abordarem temas relevantes ao trabalho, caracterizando uma abordagem quanti-qualitativa. Estas entrevistas foram realizadas no local da pesquisa, CLA, de abril a maio de 2005, conforme a disponibilidade das participantes, já que elas mesmas responderam às entrevistas, por escrito.

As perguntas norteadoras, na parte quantitativa, procuraram verificar se os aspectos analisados haviam sofrido melhora, piora ou se não tinham sido alterados pela prática regular das danças circulares sagradas. Ou seja, solicitou-se que a idosa comparasse sua saúde do período anterior ao início das danças com o momento em que elas estavam sendo questionadas. Dessa maneira, os itens avaliados foram: sono; disposição física e mental; desempenho sexual (libido); flexibilidade; postura; força muscular; tensão; dores; consciência corporal; bem estar; socialização; e sentimento como solidão, isolamento social e/ou familiar. Na parte qualitativa, a questão apresentada objetivou descobrir o significado da participação no grupo de danças circulares para as mulheres que a praticavam, relacionando-se especialmente com os benefícios que essa atividade poderia trazer às idosas.

Após o preenchimento das entrevistas, os dados quantitativos foram organizados e analisados pela contagem das freqüências das respostas, as quais foram, então, expostas em tabelas e convertidas em porcentagem. Os dados qualitativos foram analisados com base em uma aproximação da técnica de análise de conteúdo, conforme os benefícios precipitados pela dança, o que permitiu a formação de cinco categorias de respostas: mudanças físicas; sociais; emocionais; culturais e espirituais.

\section{Resultados e Discussão}

A partir das entrevistas, obteve-se a idade média de 67,75 anos, sendo a menor de 61 e a maior de 78 anos. 
O período médio de participação, no grupo de danças, foi de aproximadamente 28 meses, sendo que uma das entrevistadas não respondeu adequadamente à questão, sendo excluída deste item de avaliação.

Em relação à atividade profissional, seis eram "Do Lar", duas se intitularam como "Professora (aposentada)" e uma como "Professora (inativa)". Outra entrevistada apresentou como função ser "Dola", uma era "Assistente Social Aposentada", e a outra era "Aposentada", embora não tenha especificado a atividade profissional anterior, totalizando doze participantes.

Os resultados procuraram identificar acerca dos treze itens, se após a prática das danças circulares, os mesmos melhoraram, pioraram ou se mantiveram inalterados. Logo, em relação ao sono, pôde-se notar que cerca de $67 \%$ (oito) das mulheres tiveram melhora, e apenas 33\% (quatro) relataram não terem tido alteração neste aspecto após iniciarem a prática das danças circulares sagradas, sendo que não houve relato de piora.

A disposição física melhorou na maioria das idosas, 92\% (11), o que constituiu resultado de grande relevância, visto que somente $8 \%$ (uma) das entrevistadas afirmaram não terem tido modificação neste quesito.

A disposição mental foi incrementada em cerca de $83 \%$ (dez) da amostra, permanecendo inalterada em $17 \%$ (dois) da população, não demonstrando nenhum grau de piora.

O desempenho sexual foi avaliado em oito entrevistadas, haja vista que quatro mulheres não responderam ao item. Notou-se melhora do mesmo em 63\% (cinco) da amostra contrapondo-se à 37\% (três) das participantes que explicitaram inalteração da condição anterior à participação no grupo de danças circulares.

$\mathrm{O}$ quinto aspecto avaliado dizia respeito à flexibilidade. Esta foi ampliada por $83 \%$ (dez) das mulheres, não sendo modificada em apenas $17 \%$ (duas) das entrevistadas.

O relato de melhora na postura foi obtido em $75 \%$ (nove) da amostra, sendo que $25 \%$ (três) afirmaram não ter notado nenhuma alteração deste aspecto.

Quanto à força muscular, ela foi incrementada em 75\% (nove) da população analisada, mantendo-se constante em relação ao estado anterior à prática da dança, em $25 \%$ (três) das mulheres pesquisadas.

A melhora na tensão forneceu resultado de elevada relevância, haja vista que $100 \%$ (12) das mulheres afirmaram ter conseguido reduzir esse 
aspecto com a introdução da prática das danças circulares sagradas em suas vidas.

A questão relacionada às dores foi respondida por onze mulheres. Destas, 73\% (oito) explicitaram melhora na sintomatologia dolorosa, permanecendo o item inalterado em $27 \%$ (três) da população avaliada.

A pergunta que diz respeito à consciência corporal também foi respondida somente por onze entrevistadas. Porém, a melhora deste item foi de $100 \%$ (11) das mulheres analisadas, constituindo aspecto de grande relevância à veracidade da pesquisa bibliográfica.

O bem estar foi aprimorado em aproximadamente 83\% (dez) das idosas, não sendo alterado em somente $17 \%$ (duas) das entrevistadas.

$\mathrm{O}$ item doze demonstrou que cerca de $58 \%$ (sete) das mulheres incrementaram sua socialização, o que foi um aspecto analisado em contexto global (com a família, amigos, conhecidos, dentre outros), sendo que $42 \%$ (cinco) das mesmas não relataram piora, mas constância desta característica em seu comportamento.

A última questão explicitou que aproximadamente $67 \%$ (oito) das freqüentadoras do CLA obtiveram melhora nos sentimentos relacionados à solidão, isolamento social e/ou familiar, sendo que o mesmo item não sofreu alteração em 33\% (quatro) das praticantes.

Assim, em relação aos aspectos físicos, sociais e emocionais questionados objetivamente percebeu-se que a maioria das mulheres sentiu melhora significativa após a prática das danças circulares sagradas. Aquelas que não responderam de maneira positiva, relataram que os sintomas eram os mesmos, ou seja, não haviam piorado. A piora não foi relatada por nenhuma das participantes.

É interessante ressaltar que as idosas, de maneira geral, expuseram que a participação no grupo das danças circulares sagradas alterou suas vidas, especialmente o seu cotidiano, de forma relevante, o que pôde ser melhor compreendido pelos relatos apresentados adiante. Todavia, de acordo com as entrevistadas, o significado das danças circulares foi traduzido pela melhoria em variados aspectos de sua saúde física, psíquica, mental e espiritual, que culminaram com melhora na qualidade de vida delas.

Apesar das respostas subjetivas terem sido divididas, a partir de suas semelhanças, em cinco grupos, foi evidente o relato de melhora na disposição física global, de maior bem-estar, de aquisição ou incremento da consciência 
corporal, da força e resistência físicas, e de benefícios orgânicos e mentais no que diziam respeito à atenção e concentração.

As transformações físicas ganharam maior evidência nos seguintes relatos:

"Significa estar sempre melhor tanto na parte da saúde física... que acaba por enriquecer o aspecto mental." (W. R. C., 69 anos).

"[ . . . ] é um beneficio, eu tenho problemas reumáticos e... veio me ajudar..., melhora o corpo, não é agressiva e traz equilíbrio,... é muito boa para saúde, me trouxe qualidade de vida... é muito boa para a circulação... me sinto mais saudável.” (M. M. J. M., 69 anos).

Todaro e Jacob Filho (2004) comentam que a participação da mulher em uma atividade física, em especial aquela que forneça a recreação como a dança, proporciona-lhe boa forma física e maior energia, que refletem na melhora das condições psíquicas e sociais.

Feldenkrais (1984) afirma que a qualidade de vida de cada indivíduo está diretamente relacionada à qualidade do movimento que se realiza, sendo, portanto, bastante benéfica a prática de uma atividade que proporcione, além de bem-estar, execução correta dos movimentos, tal como acontece nas danças circulares sagradas.

As modificações sociais também foram notáveis para a maioria das participantes. As idosas mencionaram o fato de terem conquistado novas amizades fora do círculo familiar, de realizarem atividades até então incapazes para elas, e ainda de se sentirem valorizadas pelo contato estabelecido com os amigos e focalizadores. Portanto, elas se referiram às transformações sociais da seguinte maneira:

"Significa também está com meus amigos reforçando nossas amizades, trocando energia e recebendo ao mesmo tempo." (D. M. C., 63 anos).

"[ . . ] poder dançar e poder se apresentar publicamente... Nós temos muitas amizades. O grupo é um grupo de amigos." (M. M. J. M., 69 anos).

Para Barreto (2002), o fato das danças circulares sagradas empregarem a união, totalidade, igualdade e auxílio mútuos, faz com que os 
participantes se sintam amparados uns pelos outros, manifestando o que há de melhor em cada um. Além disso, esse tipo de dança identifica as qualidades e potencialidades das mulheres, auxiliando no desenvolvimento social, já que traz maior integração e cooperação.

Outrossim, ao permitir a maior convivência entre os integrantes proporciona-lhes maior confiança em si e nas outras pessoas, afastando-se $o$ sentimento de solidão e isolamento, fazendo com que as mulheres, por exemplo, adotem hábitos de vida mais alegres, tais como os passeios, as festas, que anteriormente elas não conseguiam realizar (ZAGO; SILVA, 2003).

O progresso emocional também foi notável. As praticantes das danças circulares afirmaram que após a adoção deste estilo de vida, sentiram-se melhores tanto em relação a si mesmas como em relação ao mundo. Elas narraram terem conseguido maior equilíbrio, alegria, harmonia, sentindo-se verdadeiramente felizes, tanto durante a dança como depois. Muitas chegaram a dizer que todas as preocupações e transtornos do dia se esvaíam após a atividade. Nesse sentido, pôde-se analisar alguns testemunhos:

"Eu sinto muito bem, por ter encontrado minha auto-estima..., faltava alguma coisa em minha vida e encontrei-as. Os professores dão muito valor as suas alunas, aprendi me valorizar aqui no CLA. A dança para mim preenche a minha solidão. ”(G. G. R., 75 anos).

"[...] momento de interiorização-meditação. Enfim uma maneira de ver a vida com toda sua plenitude." (A. S. A., 62 anos).

"No momento significa tudo. Estou em tratamento para depressão. Quando cheguei aqui havia passado há pouco tempo pelo pronto socorro psiquiátrico e estava quase em parafuso. Cheguei e apaixonei. Hoje estou separada do meu marido alcoólatra, estou bem, ainda não consegui sair dos remédios controlados, mas aqui eu esqueço todas as minhas tristezas. 'Eu louvo a dança'... Para mim hoje posso dizer sinceramente: não consigo mais me imaginar longe daqui, ou seja, jamais vou abandonar esse grupo enquanto vida tiver... Amo o grupo, amo as pessoas do grupo e acima de tudo amo minha dança." (I. D. O., 61 anos).

As danças circulares sagradas, para Costa (2002), desde a sua origem, tiveram o intuito de expressar sentimentos, seja sofrimento, medo, 
tristeza, morte ou alegria, amor, nascimento, esperança, sendo consideradas sinônimo de vida.

Nesse sentido, Lorthiois (2002, p. 31) relata que a dança de roda ou circular é capaz de transformar dor e sofrimento em uma "[ ... ] impalpável beleza [... ]", acrescentando que ela constitui auxílio real, sendo capaz de abolir temores, receios e angústias, e ainda de eliminar o fracasso, deixando o praticante repleto de tranqüilidade, porque ela trabalha com sentimentos de unicidade, auxílio mútuo e igualdade.

O simbolismo e a origem das danças circulares sagradas fizeram com que as idosas praticantes adquirissem também maior consciência cultural, isso porque, para se dançar, era preciso entender o que significavam os movimentos adotados, o que vinha de uma herança cultural. Assim, o focalizador passava a história da dança para as alunas, que reviviam o seu passado ou o passado da humanidade. Logo, pôde-se perceber em algumas narrativas, a maior consciência e a transformação cultural que elas foram adquirindo, conforme exposto abaixo:

"[ . . . ] a dança circular sagrada, ela é a expressão de uma cultura, tanto que a gente dança, assim músicas de vários países do mundo, expressão de cultura popular, ela é expressão de rituais sagrados, ela é expressão de significado cultural, em síntese é isso... A Cristina, na hora que ela vai ensinar a dança de qualquer país ela diz a origem, ela diz o quê que significa para aquela cultura, ela faz uma explanação sobre cada tipo... uma ampliação da cultura, do conhecimento das diversas manifestações populares dos povos do mundo inteiro... traz um conteúdo cultural muito grande.” (M. M. J. M., 69 anos).

Compartilhando deste entendimento, Costa (2002) afirma que as danças circulares retomam e revivem as maneiras que os antigos povos e as diversas culturas mundiais tinham de se expressarem, acrescentando, porém, novas criações adquiridas ao longo do tempo e em cada sociedade, bem como inovando nos ritmos, coreografias e significados inerentes à realidade de cada homem que as adotam.

Para Bonetti (2002), a dança foi a origem da cultura do povo. Ela contribuiu para a formação da identidade humana, bem como era o elo de projeção de suas atitudes em relação ao mundo. De Carlo e Bartalotti (2001) acrescentam que as atividades permitiram ao sujeito se reconhecer e ser 
reconhecido por diversos afazeres, fazendo com que se pudesse conhecer a história de vida do indivíduo e, por conseqüência, da sociedade.

O progresso espiritual também foi exposto pelas participantes do grupo avaliado. Elas afirmaram que se sentiram melhores interiormente para lidarem com as atividades diárias. Relataram que é uma maneira de manterem contato com Deus, isso porque estão com mente e coração livres, através da prática da meditação em movimento. Logo, alguns depoimentos foram relacionados:

“Adoro dançar, e é um modo de me encontrar com Deus.” (G. S., 72 anos).

“[...] preparam o meu espírito... para as tarefas diárias." (D. M. C., 63 anos).

Ribeiro (1998, p. 37) enfatiza que "[ . . . ] a dança pode ser considerada como a liturgia do corpo" revelando as mais altas expressões do ser humano, apresentando ligação direta com o Deus, maior, o que pode ser revelado pelo poder da dança em modificar a vida de quem a pratica.

Inferiu-se, pois, que as entrevistas foram unânimes em demonstrar os diversos benefícios que as danças circulares sagradas ofereceram à vida das mulheres que as adotaram como prática ou hábito de vida. E que o maior significado para as praticantes manteve relação com a qualidade de vida adquirida. Assim, o Centro Livre de Artes, e a vivência das danças circulares sagradas, representaram para a idosa, sua volta à vida, pois ela se redescobriu e se recriou. As gerontes que praticavam este tipo de dança descobriram que envelhecer era ampliar o futuro e valorizar o "eu" que passou a ser redefinido por elas mesmas.

No campo científico da saúde, a Terapia Ocupacional baseia-se na interação entre os conhecimentos médicos, sociais e entre os aspectos artísticos e práticos das atividades. Busca tratar afecções físicas e psíquicas utilizando como recursos as atividades específicas para auxiliar o paciente a atingir o máximo de sua funcionalidade e independência, podendo ser definida como " $[. .$.$] a arte e a ciência de ajudar pessoas a realizarem as atividades$ diárias que são importantes para elas, apesar de debilidades, incapacidades, ou deficiências [... ]." (NEISTADT; CREPEAU, 2002, p. 32).

Ainda, conforme Liberman (1998, p. 13), seria uma “" . . . ] prática social ocupada em observar e intervir na qualidade de vida do sujeito cujo 
olhar se volta sobre seu cotidiano, suas possibilidades de encontro consigo mesmo e com o outro [...]."

No campo da geriatria e gerontologia, o terapeuta ocupacional procura potencializar as capacidades remanescentes do geronte, auxiliando-o a tomar decisões de maneira segura, estimulando seu auto-conhecimento, auto-cuidado e independência, promovendo melhora em sua auto-estima.

De acordo com De Carlo e Bartalotti (2001), em verdade, o que se faz em relação aos idosos é ampliar a realidade, visto que a geronte, ao se submeter ao acompanhamento terapêutico ocupacional, começa a vislumbrar novas e concretas possibilidades de adquirir conhecimentos, tal como de conquistar novas linguagens, aprendendo a conviver melhor e se emancipar, criando, inclusive, novos projetos de vida.

Mas pela necessidade em se respeitar as limitações das gerontes e em contrapartida, pela urgente carência em se promover maior qualidade de vida a elas, a dança permite a expressão do corpo naturalmente, já que não excede as capacidades da praticante, proporcionando-lhe várias formas de se expressar, criar e adquirir novas consciências.

Segundo Liberman (1998), na dança o corpo além de afetar é afetado por outro corpo. Tal processo cria turbulências e transformações irreversíveis em cada sujeito que a pratica, sendo então, o fator modificador da condição do indivíduo. Assim, tanto a arte como o próprio corpo são objetos terapêuticos porque possibilitam a captação de informações, além da expressão e comunicação, ainda que subjetivamente.

As danças circulares permitem o que para Liberman (1998) é essencial: a possibilidade de se expressar conforme a sua necessidade. $\mathrm{Ou}$ seja, ninguém é obrigado a fazer o que não deseja, e o medo da falha ou da execução incorreta de um movimento é substituído pelo sentimento de satisfação advindo da superação e do auxílio mútuo dado pelos colegas. Esse tipo de dança possibilita à pessoa o contato consigo mesma, fazendo com que ela se descubra e respeite não apenas suas limitações, mas suas potencialidades.

Dentre os benefícios globais das danças circulares, nota-se que as mesmas favorecem a aquisição do centro de equilíbrio. O indivíduo passa a sentir simultaneamente os dois hemicorpos, melhorando sua percepção, lateralidade e propriocepção. Há ganho de força e resistência musculares bem como aprimoramento do controle motor, contribuindo para incremento na coordenação motora global, equilíbrio e esquema ou consciência corporais. 
Possibilita o desenvolvimento e aprimoramento das qualidades humanas. A visão, precisão, coordenação do movimento, beleza corporal, flexibilidade, criatividade e expressão, são a essência da dança levada para o dia-a-dia da participante. Há melhora significativa da postura e da qualidade de movimento, colaborando para o maior equilíbrio interno (ACHAR, 1998).

As danças circulares agem como facilitadoras da constituição de grupos, e, por conseguinte, atuam diretamente na socialização. A possibilidade de se estar de mãos dadas, de sentir a harmonia do grupo através do movimento e do ritmo, dissolve fronteiras.

Nesse sentido, a dança, no contexto da Terapia Ocupacional, passa a considerar os aspectos morfológicos, psíquicos e sociais, tendo papel fundamental de habilitar e reabilitar o indivíduo, física ou mentalmente, através de estímulos provocados pela música, ritmo e canto. Ela permite ao terapeuta utilizá-la como recurso e meio de tratamento, buscando fazer com que cada indivíduo realize movimentos expressivos para si mesmo. Por meio dela, emprega-se a visão holística de mundo, notando-se o sujeito como um todo (LÓPEZ, 2002).

Para Costa (2002), as danças circulares somente têm a acrescentar à Terapia Ocupacional e vice-versa. Para a autora, dessa forma, existirá maior possibilidade de percepção do grupo por outra via de comunicação, sendo um momento de maior pureza e amizade, sem competições, existindo, então, uma universalização da linguagem estabelecida pela comunicação através do movimento.

Logo, a Terapia Ocupacional terá como foco primordial a qualidade de vida, que será proporcionada pela melhora da condição física e do aspecto mental. Especialmente na terceira idade, e mais especificamente nas mulheres, estará relacionada a uma transformação concreta da realidade, que somente será conquistada quando a idosa internalizar as mudanças positivas que ela adquire tanto na dança como na Terapia Ocupacional. Assim, estará diretamente ligada à independência na satisfação das necessidades cotidianas.

Nesse sentido, a Terapia Ocupacional, ao lidar com as atividades, de uma forma global, contribui e complementa as danças circulares sagradas, enfatizando a idéia de equipe multi e interdisciplinar. Isto é, além de se inserir na execução das danças sagradas, desde que devidamente preparada, pode indicar a participação de suas pacientes nessa vivência para que os resultados sejam potencializados e cada vez mais efetivos. 
Evidencia-se, pois, que as danças circulares originam novas propostas de vida, compreendendo a saúde em um sentido mais amplo do que a definição rotineira de bem-estar físico-psíquico-social. Esta dança enxerga a saúde como produção de vida; e por meio de cada movimento e simbolismo, ela produz vida porque desperta as idosas para novos horizontes, o que vai de encontro à visão humanística da Terapia Ocupacional.

\section{Considerações Finais}

As danças circulares são capazes de produzir inúmeros benefícios para seus praticantes. Melhoram as disposições física e mental, a flexibilidade, a postura, a força e a resistência musculares, a consciência ou esquema corporais, reduzindo tensões e dores, e precipitando bem-estar. Atuam no campo mental e emocional porque permitem à pessoa trabalhar a atenção, memória, cognição, linguagem, bem como se expressar, socializar, e minimizar os sentimentos de isolamento e solidão.

No campo da ciência, o terapeuta ocupacional é um integrante de toda a equipe da saúde, que atua com uma visão holística do indivíduo. Analisa o problema, mas procura entender, sobretudo, sua causa e conseqüências ou implicações. É um profissional que busca maximizar as habilidades das gerontes, demonstrando a elas uma nova perspectiva de vida. Assim, baseado na conquista do bem-estar, a dança circular sagrada se torna mais um recurso possível de ser utilizado pela Terapia Ocupacional para trazer qualidade de vida às idosas.

Tanto as danças circulares sagradas como a Terapia Ocupacional enxergam a saúde como produção de vida. A dança, por ser um recurso antigo, mas simples, que utiliza como instrumento somente o corpo humano, cria um novo olhar para as participantes, promovendo modificações físicas, emocionais, sociais, espirituais e culturais. E a Terapia Ocupacional, como terapia holística que prima pela qualidade de vida por meio do uso das atividades, ao integrar esse processo, potencializa todas as transformações citadas. 


\title{
THE CIRCULAR DANCES AND THE POSSIBLE CONTRIBUTIONS OF THE OCCUPATIONAL THERAPY FOR SENIORS WOMENS
}

\begin{abstract}
The aging is still seen as a period of great difficulties and quite neglectful. The woman, especially, it is deprived of expressing their feelings or even of practicing activities that provide him/her pleasure. The challenge is in adopting activities to allow the well-being of that population. The sacred circular dances appear, in that the participants are expressed by the movement, using only the body, participating actively of their transformations and of the social modification. Like this, did took place a field research with twelve women, apprentices of the circular dances, in the Center Free from Arts, located in Goiânia (GO), with the intention of identifying the benefits of these dances in the participants' life. From ownership of the data, it tried to correlate them to the Occupational therapy, profession that looks for the maintenance of the autonomy and the individual's independence as well as his/her social integration, which can collaborate with this practice, and the opposite, to offer better life quality to the seniors.

Keywords: Third Age. Woman. Sacred Circular Dances. Occupational Therapy.
\end{abstract}

\section{REFERÊNCIAS}

ACHAR, Dalal. Balé: uma arte. Rio de Janeiro: Ediouro, 1998.

BARRETO, Sirlene. Danças Sagradas. 2002. Disponível em: <http:// www.holos.com.br>. Acesso em: 06 nov. 2004.

BONETTI, Maria Cristina de Freitas. Dança Sagrada - A Celebração da Vida. In: RAMOS, Renata Carvalho Lima (Org.). Danças Circulares Sagradas: uma proposta de educação e cura. 2. ed. São Paulo: Triom, 2002. P. 107-135. 
COSTA, Ana Lucia Borges da. Dança: uma herança à disposição de todos. In: RAMOS, Renata Carvalho Lima (Org.). Danças Circulares Sagradas: uma proposta de educação e cura. 2. ed. São Paulo: Triom, 2002. P. 17-25.

DE CARLO, Marysia Mara Rodrigues do Prado; BARTALOTTI, Celina Camargo (Org.). Terapia Ocupacional no Brasil: fundamentos e perspectivas. São Paulo: Plexus, 2001.

FELDENKRAIS, Moshe. Vida e Movimento. São Paulo: Summus, 1984.

JACOB FILHO, Wilson. Promoção da Saúde do Idoso. São Paulo: Lemos, 1998.

LIBERMAN, Flávia. Danças em Terapia Ocupacional. São Paulo: Summus, 1998.

LÓPEZ, Begoña Polônio. Terapia ocupacional em geriatría: 15 casos prácticos. Madrid: Panamericana, 2002.

LORTHIOIS, Céline. As Danças Circulares na Roda da Vida. In: RAMOS, Renata Carvalho Lima(Org.). Danças Circulares Sagradas: uma proposta de educação e cura. 2. ed. São Paulo: Triom, 2002. P. 27-41.

NEISTADT, Maurenn; CREPEAU, Elizabeth Blesedell (Org.). Willard e Spackman. Terapia Ocupacional. 9. ed. Rio de Janeiro: Guanabara Koogan, 2002.

PAPALÉO NETTO, Matheus. O Estudo da Velhice no Século XX: histórico, definição do campo e termos básicos. In: FREITAS, Elizabeth Viana de et al. Tratado de Geriatria e Gerontologia. Rio de Janeiro: Guanabara Koogan, 2002. P. 91-99.

RIBEIRO, Zilda Fernandes. A Mulher e seu Corpo: magistério eclesiástico e renovação da ética. Aparecida, SP: Santuário, 1998.

TODARO, Mônica de Ávila; JACOB FILHO, Wilson. Dança: uma atividade física de corpo e alma. In: DIOGO, Maria José D'Elboux; NERI, Anita 
Liberalesso; CACHIONI, Meire (Org.). Saúde e Qualidade de Vida na Velhice. Campinas: Alínea, 2004. P. 189-209.

ZAGO, Adriano Volnei; SILVA, Aline Soares da. Dançando com a Terceira Idade. A Terceira Idade, São Paulo, v. 14, n. 28, p. 54-73, set. 2003. 